\title{
Microscopic and macroscopic dielectric description of mixed oxide thin films
}

\author{
F. J. Ferrer \\ Centro Nacional de Aceleradores, C/Thomas A. Edison, 7, E-41092 Sevilla, Spain \\ F. Yubero ${ }^{\text {a) }}$ \\ Instituto de Ciencia de Materiales de Sevilla (CSIC-Universidad de Sevilla) C/Américo Vespucio 49, \\ E-41092 Sevilla, Spain \\ J. A. Mejías \\ Departamento de Ciencias Ambientales, Universidad Pablo de Olavide, Ctra Utrera km 1, \\ E-41013 Sevilla, Spain \\ F. J. García-Lopez \\ Centro Nacional de Aceleradores, C/Thomas A. Edison, 7, E-41092 Sevilla, Spain \\ A. R. González-Elipe \\ Instituto de Ciencia de Materiales de Sevilla (CSIC-Universidad de Sevilla) C/Américo Vespucio 49, \\ E-41092 Sevilla, Spain
}

(Received 9 July 2007; accepted 31 August 2007; published online 30 October 2007)

\begin{abstract}
Compact $\mathrm{Si}-\mathrm{Ti}-\mathrm{O}$ and $\mathrm{Si}-\mathrm{Zr}-\mathrm{O}$ mixed oxide thin films are studied by optical characterization (refractive index, band gap energy) and local probes (Auger parameter obtained by x-ray photoelectron spectroscopy). Interpretation of the obtained results is discussed in the framework of the classical dielectric theory that correlates the macroscopic refractive index to the microscopic electronic polarizability of each particular ion in the compound through the Lorentz-Lorenz relationship. Quantum mechanical cluster calculations have also been performed to support the correlations obtained between the experimental findings. (C) 2007 American Institute of Physics.

[DOI: 10.1063/1.2801402]
\end{abstract}

\section{INTRODUCTION}

A way to precisely control the optical properties of oxide materials is to adjust the relative concentration of two single oxides mixed in a single phase. ${ }^{1-4}$ The range of variation of the refractive index $n$ and extinction coefficient $k$ achieved in this way can be very wide, particularly if the two oxides mixed together have rather different $n$ and band gap energies $E_{g}$. In the final mixed oxides, the actual values of the macroscopic quantities $n, k$, and $E_{g}$ are tightly connected with the local electronic structure of the materials, whereby the polarizability of the constituent ions, or the existence of specific electronic transitions plays a key role. In this context, it is of key importance to be able to distinguish between just mixed phases (solid solution of pure single oxide phases) or the formation of advanced materials with characteristic local and extensive properties.

Information about microscopic electronic parameters such as binding energies of certain photoemission peaks, Auger parameters, extra-atomic relaxation energies, or the initial state energies of the system before the photoemission event can be gathered by means of $\mathrm{x}$-ray photoemission spectroscopy (XPS). ${ }^{5,6}$ However, the establishment of relationships between these local electronic parameters and extensive optical properties such as $n$ or $E_{g}$ of a given material has only been intended a few times in the literature. ${ }^{7,8}$ In this

\footnotetext{
${ }^{a)}$ Author to whom correspondence should be addressed. Electronic mail: yubero@icmse.csic.es
}

context, the use of the so called Auger parameter ${ }^{5,9}$ derived from the XPS measurements can be a powerful approximation that can justify the changes in the optical properties of the mixed oxide materials as a function of their composition. Besides, the use of quantum mechanical calculations with cluster models may provide an extra theoretical framework to account for the changes in their electronic parameters. ${ }^{10,11}$

In the present work, we study the connection between the optical properties and some electronic parameters derived from XPS analysis of mixed oxides materials ( $\mathrm{Si}-\mathrm{Ti}-\mathrm{O}$ and $\mathrm{Si}-\mathrm{Zr}-\mathrm{O}$ thin films with different $\mathrm{M} / \mathrm{Si}$ proportions, $\mathrm{M}$ : Ti and $\mathrm{Zr}$ ). These two systems have been chosen due to the large range of variation between $\mathrm{SiO}_{2}$ and $\mathrm{TiO}_{2} / \mathrm{ZrO}_{2}$ single oxides for their refractive index (e.g., around 1.45 and 2.55/2.10 for bulk $\mathrm{SiO}_{2}$ and $\mathrm{TiO}_{2} / \mathrm{ZrO}_{2}$, respectively) ${ }^{12-14}$ and their band gap energies (e.g., 8.5 and 3.2/5.0 eV for bulk $\mathrm{SiO}_{2}$ and $\mathrm{TiO}_{2} / \mathrm{ZrO}_{2}$, respectively). ${ }^{4,15}$ A preliminary study for the $\mathrm{Si}-\mathrm{Ti}-\mathrm{O}$ mixed oxide thin films can be found in Ref. 16.

\section{EXPERIMENTAL}

Mixed oxides $\mathrm{Si}-\mathrm{Ti}-\mathrm{O}$ and $\mathrm{Si}-\mathrm{Zr}-\mathrm{O}$ thin films, with thicknesses around 100-300 nm, have been prepared by ion beam induced chemical vapor deposition ${ }^{17}$ (IBICVD) and plasma enhanced chemical vapor deposition (PECVD). ${ }^{18}$ Samples with different $\mathrm{Si} / \mathrm{Ti}$ and $\mathrm{Si} / \mathrm{Zr}$ atomic ratios were obtained by changing the relative partial pressures of the corresponding precursors of $\mathrm{Si}, \mathrm{Ti}$, and $\mathrm{Zr}$. Thus, the $\mathrm{Si}-\mathrm{Ti}-\mathrm{O}$ 
thin films with more than $10 \% \mathrm{Ti}$ were prepared at room temperature by IBICVD with $400 \mathrm{eV} \mathrm{O}_{2}^{+}$ions, using $\mathrm{Si}\left(\mathrm{C}_{2} \mathrm{H}_{5} \mathrm{O}\right)_{3} \mathrm{Cl}$ and $\mathrm{TiCl}_{4}$ volatile precursors and $\mathrm{O}_{2}{ }^{+}$ions. $\mathrm{Si}-\mathrm{Ti}-\mathrm{O}$ samples with less than $10 \% \mathrm{Ti}$ were prepared by PECVD at $523 \mathrm{~K}^{18}$ The $\mathrm{Si}-\mathrm{Zr}-\mathrm{O}$ thin films were also prepared by IBICVD at room temperature using $\left(\mathrm{CH}_{3} \mathrm{CH}_{2} \mathrm{O}\right)_{3} \mathrm{SiH}$ and $\mathrm{Zr}\left[\mathrm{O}\left(\mathrm{CH}_{2}\right)_{3} \mathrm{CH}_{3}\right]_{4}$ volatile precursors and $\mathrm{O}_{2}{ }^{+}+\mathrm{Ar}^{+} 400 \mathrm{eV}$ ions.

The films were amorphous and homogeneous in depth as determined by Rutherford backscattering spectrometry. This technique, together with $\mathrm{x}$-ray fluorescence, was used to determine the composition of the films. Their bonding structure was examined by Fourier transform infrared spectroscopy (FTIR) and by x-ray absorption spectroscopy and their optical properties determined by UV-visible absorption spectroscopy and spectroscopic ellipsometry. A full account of the characterization can be found in Refs. 19 and 20.

XPS spectra were recorded with VG-Escalab210 and Specs-Phoibos 100 spectrometers and using an unmonochromatized $\mathrm{Al} K_{\alpha}$ excitation source. As a reference for binding energy calibration, the $\mathrm{C} 1 \mathrm{~s}$ peak of the air adventitious carbon contaminating the surface of samples was taken at a value of $284.6 \mathrm{eV}$. All the samples presented some charging displacement in peaks positions of about $2-4 \mathrm{eV}$. The samples were introduced in the chamber and examined without any additional cleaning treatment. Auger parameters ${ }^{5,9}$ of silicon $\alpha_{\mathrm{Si}}^{\prime}$, titanium $\alpha_{\mathrm{Ti}}^{\prime}$ and zirconium $\alpha_{\mathrm{Zr}}^{\prime}$ cations in the films were defined as

$$
\begin{aligned}
& \alpha_{\mathrm{Si}}^{\prime}=\mathrm{BE}(\mathrm{Si} 2 p)+\mathrm{KE}(\mathrm{Si} K V V), \\
& \alpha_{\mathrm{Ti}}^{\prime}=\mathrm{BE}\left(\mathrm{Ti} 2 p_{3 / 2}\right)+\mathrm{KE}(\mathrm{Ti} L M V), \\
& \alpha_{\mathrm{Zr}}^{\prime}=\mathrm{BE}\left(\mathrm{Zr} 3 d_{5 / 2}\right)+\mathrm{KE}\left(\mathrm{Zr} L M_{4,5} M_{4,5}\right),
\end{aligned}
$$

where $\mathrm{BE}$ and $\mathrm{KE}$ refer to the binding energy of the photoemitted peak and kinetic energy of the Auger transition in parenthesis.

Reflection electron energy loss spectroscopy (REELS) measurements were recorded in the VG spectrometer using a primary electron beam of $1500 \mathrm{eV}$ that was supplied with a LEG62 electron gun from VG.

For the quantum mechanical calculations, we have considered cluster models similar to those used previously by some of us. ${ }^{10,11}$ To account for the nearest environments of the $\mathrm{Si}, \mathrm{Ti}$, and $\mathrm{Zr}$ atoms, we use small clusters in which the $\mathrm{Si}$ and $\mathrm{M}(\mathrm{M}=\mathrm{Zr}, \mathrm{Ti})$ are connected through one or two oxygen atoms, and then the coordinations of both $\mathrm{Si}$ and $\mathrm{M}$ are completed with $\mathrm{OH}$ or $\mathrm{H}_{2} \mathrm{O}$ fragments. The resulting structures are optimized by means of Density functional theory $^{21}$ (DFT) calculations using the B3LYP exchangecorrelation potential ${ }^{22}$ and $6-31 \mathrm{G}^{* *}$ basis set ${ }^{23}$ on all atoms except for $\mathrm{Zr}$ for which SDD basis set and core pseudopotential $^{24}$ are used. The electronic excitation energies are then calculated using time dependent DFT-B3LYP theory ${ }^{25}$ and including the lower 40 singlet excited states. For the calculation of the relaxation energies, we make use of the $\mathrm{Z}+1$ approximation, in which the effect of the core hole formation on the valence electrons is simulated increasing by one the atomic number of the metal and adding a

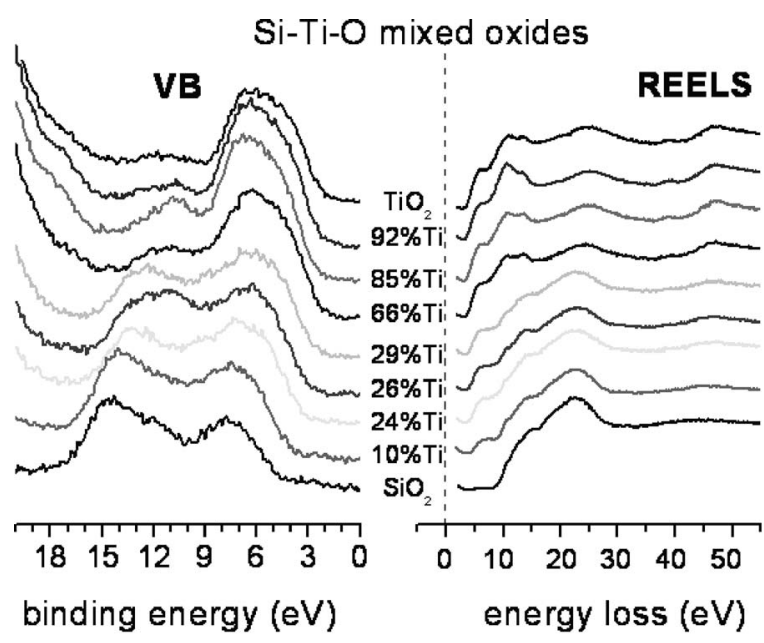

FIG. 1. XPS valence band (left) and REELS (right) spectra of Si-Ti-O thin films.

positive charge to the cluster. The extra-atomic relaxation energy is calculated as the difference between the relaxation energy of the cluster with $\mathrm{Ti}, \mathrm{Zr}$, or $\mathrm{Si}$, and the energy of the $\mathrm{Ti}^{+4}, \mathrm{Zr}^{+4}$, or $\mathrm{Si}^{+4}$ free ions. In these calculations a $6-31 \mathrm{G}^{*}$ basis set is used for $\mathrm{P}$ and $\mathrm{V}$ and SDD including core pseudopotential for $\mathrm{Nb}$. All the calculations are made with the GAUSSIAN03 program. ${ }^{26}$

\section{RESULTS}

\section{A. Valence band photoemission, low loss electron energy losses, and band gap energy}

XPS provides a view of the occupied valence band density of states of the analyzed mixed oxide materials. Figures 1 (left) and 2 (left) show the evolution of the valence band spectra of these $\mathrm{Si}-\mathrm{M}-\mathrm{O}(\mathrm{M}: \mathrm{Ti} / \mathrm{Zr})$ mixed oxides from the situation of $\mathrm{SiO}_{2}$ (bottom) to that of $\mathrm{TiO}_{2}$ and $\mathrm{ZrO}_{2}$ (top), respectively. Note that the onset of the valence band is progressively shifted to lower binding energies as the content on $\mathrm{Ti} / \mathrm{Zr}$ in the mixed oxides is increased.

On the other hand, REELS provides a clear view of the electronic transitions from the occupied states at the top of the valence band to the unoccupied states at the bottom of the conduction band. Figures 1 (right) and 2 (right) show the evolution of the REELS spectra of these $\mathrm{Si}-\mathrm{M}-\mathrm{O}(\mathrm{M}: \mathrm{Ti} / \mathrm{Zr}$ ) mixed oxides from the situation of $\mathrm{SiO}_{2}$ (bottom) to that of

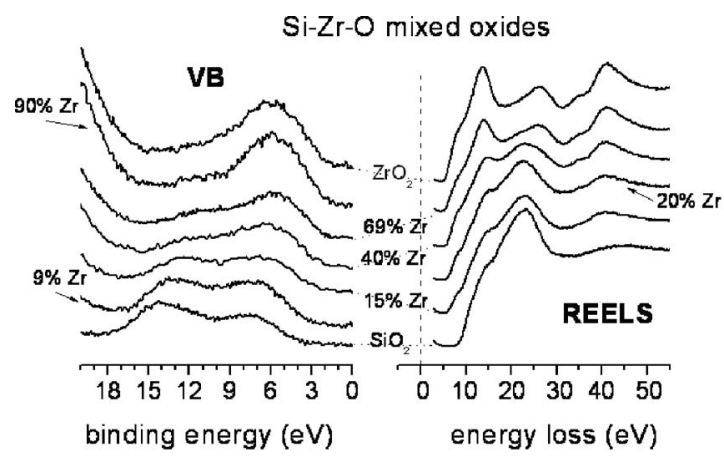

FIG. 2. XPS valence band (left) and REELS (right) spectra of $\mathrm{Si}-\mathrm{Zr}-\mathrm{O}$ thin films. 


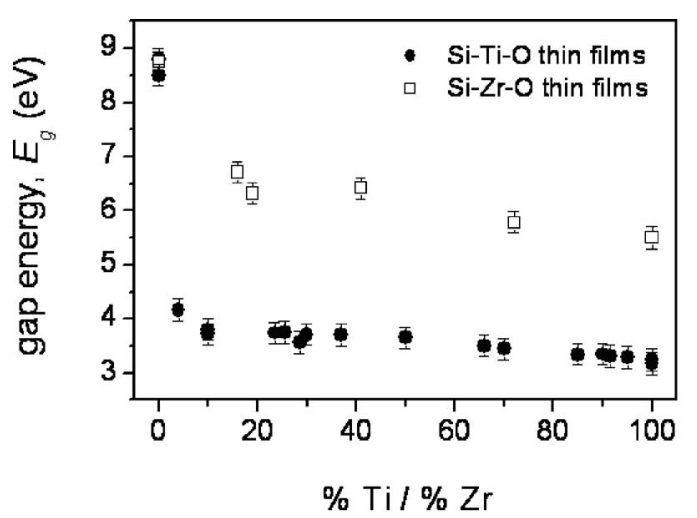

FIG. 3. Band gap energy $E_{g}$ of $\mathrm{Si}-\mathrm{Ti}-\mathrm{O}$ (bold dots) and $\mathrm{Si}-\mathrm{Zr}-\mathrm{O}$ (open squares) mixed oxide thin films as a function of the percentage of $\mathrm{Ti} / \mathrm{Zr}$.

$\mathrm{TiO}_{2}$ and $\mathrm{ZrO}_{2}$ (top), respectively. In this case, transitions appear inside the wide $\mathrm{SiO}_{2}$ band gap $(>8 \mathrm{eV})$ as soon as the weakest amount of $\mathrm{Ti} / \mathrm{Zr}$ is incorporated in the mixed oxides. Besides, the onset of these energy losses is progressively shifted to lower energy losses as the content on $\mathrm{Ti} / \mathrm{Zr}$ in the mixed oxides is increased. As it is well known, the onset of these energy losses is a measure of the band gap energy $E_{g}$ of the analyzed mixed oxide material. ${ }^{27}$

Figure 3 shows the gap $E_{g}$ of the $\mathrm{Si}-\mathrm{Ti}-\mathrm{O}$ and $\mathrm{Si}-\mathrm{Zr}-\mathrm{O}$ mixed oxide thin films. The evolution profile of $E_{g}$ is characterized by a sharp decay from the value of $\mathrm{SiO}_{2}$ [i.e., $>8 \mathrm{eV}$ (Ref. 27)] to that of a sample with $\sim 2 \%$ Ti or $15 \%$ $\mathrm{Zr}$ with $E_{g}$ of approximately 4 and $6 \mathrm{eV}$, respectively. This sharp decrease is followed by a smoother decrease to reach the value of pure $\mathrm{TiO}_{2}$ [i.e., $3.2 \mathrm{eV}$ (Refs. 13 and 15)] and pure $\mathrm{ZrO}_{2}$ [i.e., $5.0 \mathrm{eV}$ (Refs. 15, 28, and 29)].

\section{B. Refractive index}

Figure 4 shows the refractive index $n$ at $\lambda=550 \mathrm{~nm}$ in the $\mathrm{Si}-\mathrm{Ti}-\mathrm{O}$ and $\mathrm{Si}-\mathrm{Zr}-\mathrm{O}$ mixed oxide thin films. Note that for both mixed oxides $n$ increases steadily with the amount of $\mathrm{Ti}$ or $\mathrm{Zr}$ in the films from $n=1.45$ for $\mathrm{SiO}_{2}$ to $n=2.35$ for $\mathrm{TiO}_{2}$ or $n=1.95$ for $\mathrm{ZrO}_{2}$.

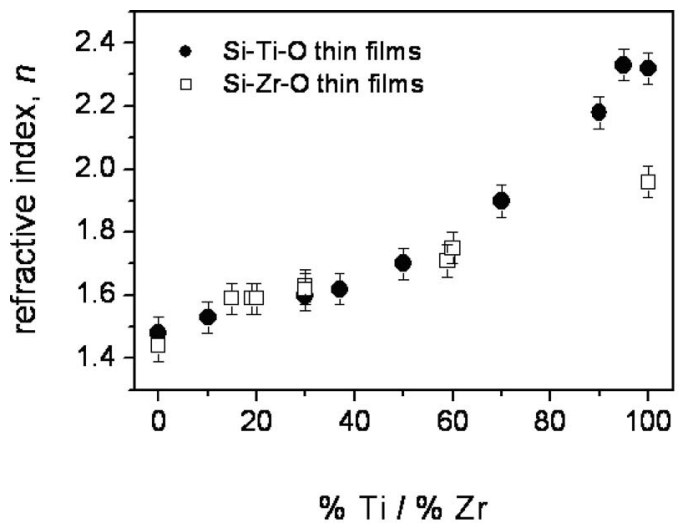

FIG. 4. Refractive index $n$ at $\lambda=550 \mathrm{~nm}$ for $\mathrm{Si}-\mathrm{Ti}-\mathrm{O}$ (bold dots) and $\mathrm{Si}-$ $\mathrm{Zr}-\mathrm{O}$ (open squares) mixed oxide thin films as a function of the percentage of $\mathrm{Ti} / \mathrm{Zr}$.
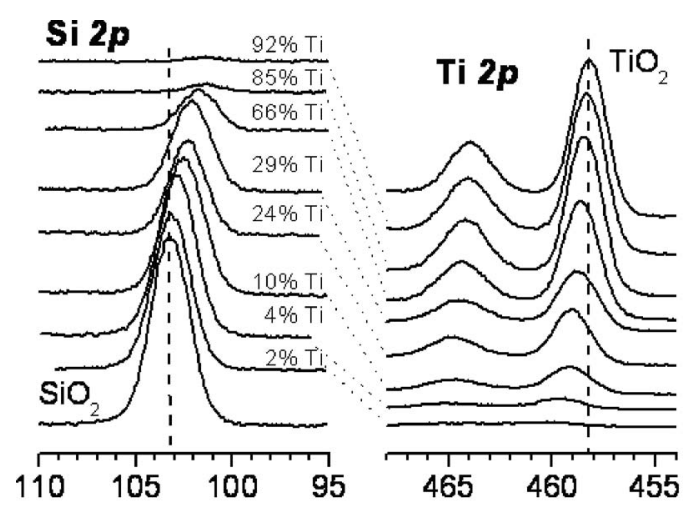

Binding energy $(\mathrm{eV})$

FIG. 5. Si $2 p$ (left) and Ti $2 p$ (right) photoemission spectra of Si-Ti-O mixed oxide thin films with different contents of Ti.

\section{Core level photoemission}

Figure 5 (Fig. 6) shows a series of Si $2 p$ and Ti $2 p(\operatorname{Si} 2 p$ and $\mathrm{Zr} 3 d$ ) photoemission spectra for the $\mathrm{Si}-\mathrm{Ti}-\mathrm{O}(\mathrm{Si}-\mathrm{Zr}-\mathrm{O})$ mixed oxide thin films. It is interesting that the binding energy of the Si $2 p$, and Ti $2 p / \mathrm{Zr} 3 d$ peaks changes with the amount of $\mathrm{Ti} / \mathrm{Zr}$ in the films. A similar effect is found when looking to the kinetic energies of the corresponding Ti $L M V$, $\mathrm{Zr} L M M$, and Si $K V V$ Auger peaks (not shown). As a result, the Auger parameters ${ }^{5,9}$ of silicon $\alpha_{\mathrm{Si}}^{\prime}$, titanium $\alpha^{\prime}{ }_{\mathrm{Ti}}$, and zirconium $\alpha^{\prime}{ }_{\mathrm{Zr}}$ cations in the films change to a large extent when comparing the values of the different samples. An advantage of using the Auger parameter instead of the BE of photoemission peaks to distinguish between different mixed oxide films is that the former is not affected by charging effects on the samples. Plots of $\alpha^{\prime}{ }_{\mathrm{Si}}$ and $\alpha^{\prime}{ }_{\mathrm{Ti}} / \alpha^{\prime}{ }_{\mathrm{Zr}}$ as a function of the percentage of $\mathrm{Ti}$ and $\mathrm{Zr}$ in the $\mathrm{Si}-\mathrm{Ti}-\mathrm{O}$ and $\mathrm{Si}-$ $\mathrm{Zr}-\mathrm{O}$ mixed oxide films are reported in Figs. 7 and 8, respectively. In Fig. 7 we observe that both $\alpha^{\prime}{ }_{\mathrm{Ti}}$ and $\alpha_{\mathrm{Si}}^{\prime}$ increase by $\sim 2.0 \mathrm{eV}$ when going from pure $\mathrm{SiO}_{2}$ to pure $\mathrm{TiO}_{2}$ samples. Similarly, Fig. 8 shows that $\alpha^{\prime}{ }_{\mathrm{Zr}}$ and $\alpha^{\prime}{ }_{\mathrm{Si}}$ increase by $\sim 1.5 \mathrm{eV}$ when going from pure $\mathrm{SiO}_{2}$ to pure $\mathrm{ZrO}_{2}$ samples.

From the binding energies of the Si $2 p$, Ti $2 p$, and $\mathrm{Zr} 3 d$ and the corresponding Auger parameters, we have deter-

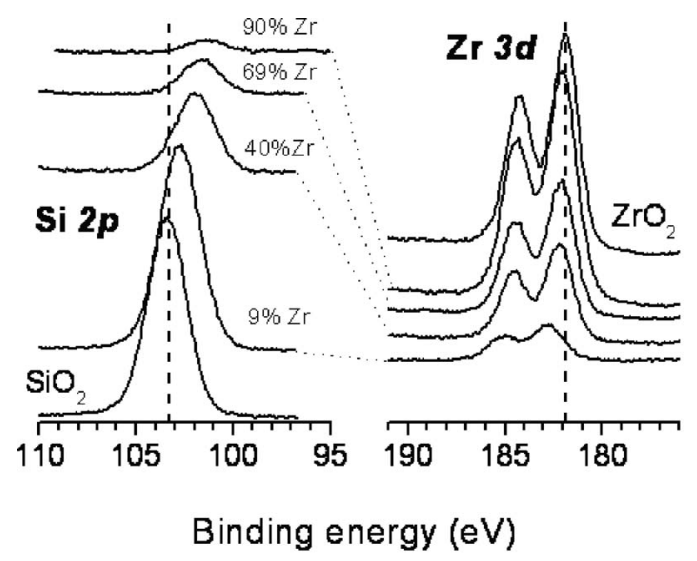

FIG. 6. Si $2 p$ (left) and $\mathrm{Zr} 3 d$ (right) photoemission spectra of $\mathrm{Si}-\mathrm{Zr}-\mathrm{O}$ mixed oxide thin films with different contents of $\mathrm{Zr}$. 


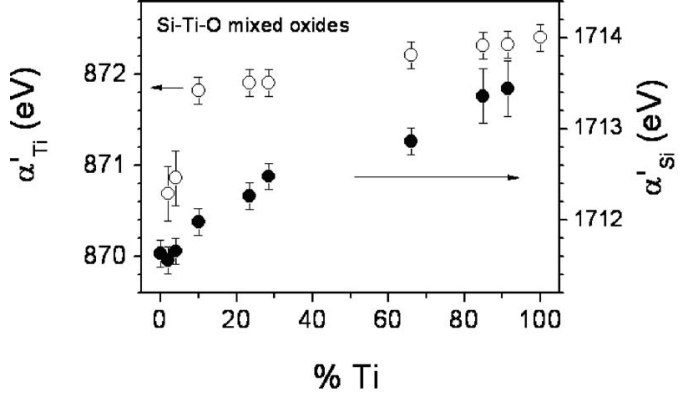

FIG. 7. Auger parameter of $\mathrm{Si}^{4+}$ ions $\alpha^{\prime}{ }_{\mathrm{Si}}$ (bold dots) and $\mathrm{Ti}^{4+}$ ions $\alpha^{\prime}{ }_{\mathrm{Ti}}$ (open circles) ions in $\mathrm{Si}-\mathrm{Ti}-\mathrm{O}$ thin films as a function of the Ti content.

mined the maximum variation in the binding energy of photoemitted peak $\Delta \mathrm{BE}_{\max }$ and the Auger parameter $\Delta \alpha^{\prime}{ }_{\max }$ for each $\mathrm{Si}-\mathrm{M}-\mathrm{O}(\mathrm{M}: \mathrm{Ti}, \mathrm{Zr})$ as

$$
\begin{aligned}
& \Delta \mathrm{BE}_{\max }=\mathrm{BE}(\mathrm{M}-\mathrm{O}-\mathrm{Si})-\mathrm{BE}(\mathrm{M}-\mathrm{O}-\mathrm{M}), \\
& \Delta \alpha^{\prime}{ }_{\text {max }}=\alpha^{\prime}(\mathrm{M}-\mathrm{O}-\mathrm{Si})-\alpha^{\prime}(\mathrm{M}-\mathrm{O}-\mathrm{M}),
\end{aligned}
$$

where $\alpha^{\prime}(\mathrm{M}-\mathrm{O}-\mathrm{M})$ and $\mathrm{BE}(\mathrm{M}-\mathrm{O}-\mathrm{M})$ are the Auger parameter and binding energy of the selected core level of the $\mathrm{M}^{4+}$ ions in bulk $\mathrm{MO}_{2}$, while $\alpha^{\prime}(\mathrm{M}-\mathrm{O}-\mathrm{Si})$ and $\mathrm{BE}(\mathrm{M}-\mathrm{O}-\mathrm{Si})$ are the Auger parameter and binding energy of the selected core level of the $\mathrm{M}^{4+}$ ion for the samples measured with lowest $\mathrm{M}$ concentration. Thus, relevant electronic parameters such as the change of extra-atomic relaxation energy of the photoholes $\Delta R_{\mathrm{ea}}$ (evaluated as half of $\Delta \alpha^{\prime}{ }_{\max }$ ) or the change in the initial state energy of the system $\Delta \varepsilon$ before photoemission (evaluated as the addition of $\left.\Delta \mathrm{BE}_{\max }+\Delta R_{\text {ea }}\right)^{6}$ can be calculated. Note that these values are representative of the different characteristics of $\mathrm{M}^{4+}$ ions diluted in a $\mathrm{SiO}_{2}$ matrix and in a $\mathrm{MO}_{2}$ oxide. A similar analysis can be performed for the $\mathrm{Si}^{4+}$ ions defining $\Delta \mathrm{BE}_{\max }, \Delta \alpha^{\prime}{ }_{\text {max }} \Delta R_{\text {ea }}$, and $\Delta \varepsilon$ with respect to the data obtained from pure $\mathrm{SiO}_{2}$. A summary of these values obtained from the $\mathrm{Si}-\mathrm{Ti}-\mathrm{O}$ and $\mathrm{Si}-\mathrm{Zr}-\mathrm{O}$ systems is reported in Tables I and II, respectively.

\section{Quantum mechanical calculations with cluster models}

In previous publications we have shown the possibility to account for the variations of extra-atomic relaxation energies $\Delta R_{\text {ea }}$ and band gap energies $E_{g}$ of transition metal cations in metal oxides, when their structure changes from a $\mathrm{M}-\mathrm{O}-\mathrm{M}$ to a $\mathrm{M}-\mathrm{O}-\mathrm{M}^{\prime}$ local environment, by means of

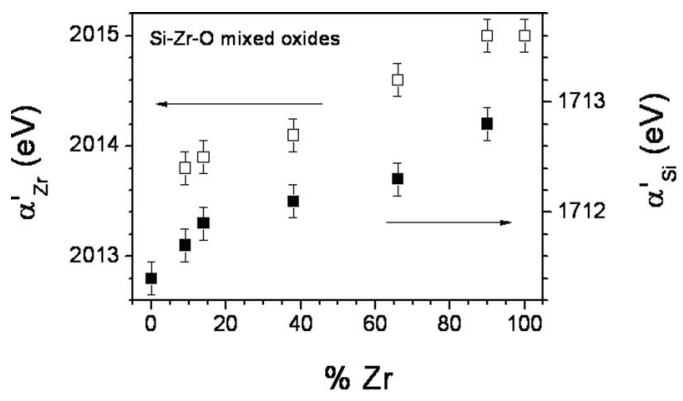

FIG. 8. Auger parameter of $\mathrm{Si}^{4+}$ ions $\alpha^{\prime}{ }_{\mathrm{Si}}$ (bold squares) and $\mathrm{Zr}^{4+}$ ions $\alpha_{\mathrm{Zr}}^{\prime}$ (open squares) in $\mathrm{Si}-\mathrm{Zr}-\mathrm{O}$ thin films as a function of the $\mathrm{Zr}$ content.
TABLE I. $\Delta \mathrm{BE}_{\max }, \Delta \alpha^{\prime}{ }_{\text {max }}, \Delta R_{\text {ea }}$, and $\Delta \varepsilon$ of $\mathrm{Ti}^{4+}$ and $\mathrm{Si}^{4+}$ cations in $\mathrm{Si}-$ Ti-O mixed oxide thin films obtained from XPS measurements (all energies in $\mathrm{eV}$ ).

\begin{tabular}{cccccc}
\hline \hline System & & $\Delta \mathrm{BE}_{\text {max }}(\mathrm{eV})$ & $\Delta \alpha_{\text {max }}^{\prime}(\mathrm{eV})$ & $\Delta R_{\text {ea }}(\mathrm{eV})$ & $\Delta \varepsilon(\mathrm{eV})$ \\
\hline Si-Ti-O & $\mathrm{Ti}^{4+}$ & $(\mathrm{Ti} 2 p)$ & & & \\
& & 2.1 & -1.7 & -0.85 & 1.25 \\
& $\mathrm{Si}^{4+}$ & $(\mathrm{Si} 2 p)$ & & & \\
& & -1.9 & 1.8 & 0.9 & -1.0 \\
\hline \hline
\end{tabular}

quantum mechanical (QM) calculations with clusters models. ${ }^{10,30}$ Similar calculations have been carried out here with clusters that model the local environments of $\mathrm{Si}$, Ti, and $\mathrm{Zr}$ in the investigated mixed oxide thin films. Schematic representations of the clusters used in the QM calculations are drawn in Fig. 9. Tetrahedral ( $\mathrm{t}$ ) and octahedral (o) coordinated $\mathrm{M}^{4+}$ cations are considered connected either by 1 or 2 bridging oxygen atoms. The results of these QM calculations are reported in Tables III and IV. These tables include calculated $E_{g}$ energies, defined as the energy difference between the highest occupied molecular orbital and lowest unoccupied molecular orbital of these clusters. They also contain relaxation energies in the final states $R_{\text {ea }}$ by assuming that a core electron has been extracted from the $\mathrm{Si} 2 p$, Ti $2 p$, or $\mathrm{Zr}$ $3 d$ levels (the energy of free $\mathrm{Si}^{4+} \rightarrow \mathrm{P}^{5+}$, free $\mathrm{Ti}^{4+} \rightarrow \mathrm{V}^{5+}$, and free $\mathrm{Zr}^{4+} \rightarrow \mathrm{Nb}^{5+}$ has been subtracted to all the values given in the table). Details about the used approximation can be found in Ref. 10 These tables also report on the differences in the relaxation energies in the final state according to the actual local environment of the cations (i.e., depending on the type of clusters). The differences have been calculated by assuming the clusters $\mathrm{Si}(\mathrm{t})-\mathrm{Si}(\mathrm{t})-1, \operatorname{Ti}(\mathrm{o})-\mathrm{Ti}(\mathrm{o})$, and $\mathrm{Zr}(\mathrm{o})$ $\mathrm{Zr}(\mathrm{o})$ (see Fig. 9 and Tables III and IV) as representative of pure $\mathrm{SiO}_{2}, \mathrm{TiO}_{2}$, and $\mathrm{ZrO}_{2}$, respectively. The calculated values can be directly compared with the measured values of $\Delta R_{\text {ea }}$ reported in Tables I and II. It appears that the calculated and measured values of $\Delta R_{\mathrm{ea}}$ show a good correlation with, in some cases, quantitative agreement. Thus, for example, according to the QM calculations, larger difference in relaxation energy at the $\mathrm{Si}^{4+}$ sites are expected for the $\mathrm{Si}-\mathrm{Ti}-\mathrm{O}$ system $(1.0 \mathrm{eV})$ than for the $\mathrm{Si}-\mathrm{Zr}-\mathrm{O}$ system $(0.7 \mathrm{eV})$, that is supported by the experimental findings.

\section{DISCUSSION}

\section{A. Electronic parameters and composition of the films}

The values of the experimentally determined electronic parameters (cf. Tables I and II) correlate with the differences

TABLE II. $\Delta \mathrm{BE}_{\max }, \Delta \alpha^{\prime}{ }_{\max }, \Delta R_{\mathrm{ea}}$, and $\Delta \varepsilon$ of $\mathrm{Zr}^{4+}$ and $\mathrm{Si}^{4+}$ cations in $\mathrm{Si}-$ $\mathrm{Zr}-\mathrm{O}$ mixed oxide thin films obtained from XPS measurements (all energies in $\mathrm{eV}$ ).

\begin{tabular}{cccccc}
\hline \hline System & & $\Delta \mathrm{BE}_{\text {max }}(\mathrm{eV})$ & $\Delta \alpha^{\prime}{ }_{\text {max }}(\mathrm{eV})$ & $\Delta R_{\text {ea }}(\mathrm{eV})$ & $\Delta \varepsilon(\mathrm{eV})$ \\
\hline $\mathrm{Si}-\mathrm{Zr}-\mathrm{O}$ & $\mathrm{Zr}^{4+}$ & $\left(\mathrm{Zr} \mathrm{3} d_{5 / 2}\right)$ & & & \\
& & 0.4 & -0.9 & -0.45 & -0.05 \\
& $\mathrm{Si}^{4+}$ & $(\mathrm{Si} 2 p)$ & & & \\
& & -1.7 & 1.4 & 0.7 & -1.0 \\
\hline \hline
\end{tabular}




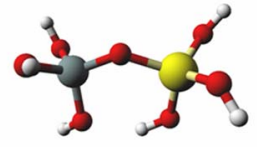

$\operatorname{Si}(\mathrm{t})-\mathrm{M}(\mathrm{t})-1$

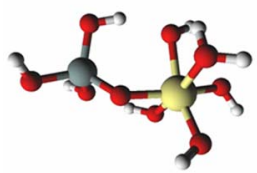

$\mathrm{Si}(\mathrm{t})-\mathrm{M}(0)-1$

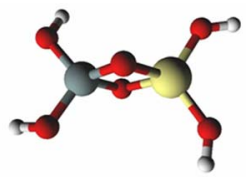

Si(t)-M(t)-2

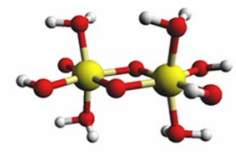

$M(0)-M(0)$
FIG. 9. (Color online) Schematic representation of the Si-M (M: Si, Ti, Zr) clusters used in the quantum mechanical calculations. (t) refers to tetrahedral coordination, (o) refers to octahedral coordination.

in the electron density distribution at the cations, their actual coordination, and the differences in the polarizabilities of the environment.

Referring to the local environment of the $\mathrm{Ti}^{4+}$ ions in $\mathrm{Si}-\mathrm{Ti}-\mathrm{O}$ mixed oxides, the obtained negative values of the corresponding $\Delta \alpha^{\prime}{ }_{\text {max }}$ and $\Delta R_{\mathrm{ea}}$ indicate that relaxation of the photoholes at the Ti sites is more favorable (i.e., more energy is released) when the surrounding matrix is $\mathrm{TiO}_{2}$-like than when it is $\mathrm{SiO}_{2}$-like. This is confirmed by the QM cluster calculations reported in Table III. The opposite occurs for the photoholes at the $\mathrm{Si}$ sites that relax more easily when the $\mathrm{Si}^{4+}$ ion is diluted within the $\mathrm{TiO}_{2}$ matrix. A similar conclusion can be met for the case of the $\mathrm{Si}-\mathrm{Zr}-\mathrm{O}$ mixed oxide thin films from Tables II and IV.

The QM cluster calculations reported in Tables III and IV provide additional evidences about the importance of changing the local coordination of the $\mathrm{Ti}^{4+}$ and $\mathrm{Zr}^{4+}$ cations when they are present in small concentrations in the films. Previous spectroscopic studies by FTIR and x-ray absorption near edge structure spectroscopies of the $\mathrm{Si}-\mathrm{Ti}-\mathrm{O}$ mixed oxide films have revealed that for concentrations of $\mathrm{Ti}$ below $30 \%$, the majority of the $\mathrm{Ti}^{4+}$ ions in the glass films present a tetrahedral coordination. A similar situation is expected for $\mathrm{Zr}$ in the $\mathrm{Si}-\mathrm{Zr}-\mathrm{O}$ films. ${ }^{31}$ According to the calculations in Tables III and IV, $\Delta R_{\text {ea }}$ values of the different cations are affected by both the presence of $\mathrm{Si}-\mathrm{O}-\mathrm{M}$ cross linking structures (M:Ti or $\mathrm{Zr}$ ) and the local coordination around them. In this regard, the presence of a tetrahedral coordination, par-

TABLE III. $E_{g}$ and $R_{\text {ea }}$ obtained from QM cluster calculation (see Fig. 9). The energy of free $\mathrm{Ti}^{+4} \rightarrow \mathrm{V}^{+5}$ or free $\mathrm{Si}^{+4} \rightarrow \mathrm{P}^{+5}$ has been subtracted to all the $R_{\mathrm{ea}}$ values given in the table. The corresponding $\Delta R_{\mathrm{ea}}$ are indicated in parenthesis.

\begin{tabular}{ccll}
\hline \hline Cluster & $E_{g}(\mathrm{eV})$ & $\begin{array}{c}R_{\mathrm{ea}}\left(\Delta R_{\mathrm{ea}}\right)(\mathrm{eV}) \\
\mathrm{Ti}^{4+} \rightarrow \mathrm{V}^{5+}\end{array}$ & $\begin{array}{c}R_{\mathrm{ea}}\left(\Delta R_{\mathrm{ea}}\right)(\mathrm{eV}) \\
\mathrm{Si}^{4+} \rightarrow \mathrm{P}^{5+}\end{array}$ \\
\hline $\mathrm{Si}(\mathrm{t})-\mathrm{Si}(\mathrm{t})-1$ & 7.72 & & $62.22(0.00)$ \\
$\mathrm{Si}(\mathrm{t})-\mathrm{Si}(\mathrm{t})-2$ & 7.31 & & $62.19(-0.03)$ \\
$\mathrm{Ti}(\mathrm{t})-\mathrm{Si}(\mathrm{t})-1$ & 5.40 & $64.48(-1.33)$ & $62.57(0.35)$ \\
$\mathrm{Ti}(\mathrm{t})-\mathrm{Si}(\mathrm{t})-2$ & 4.73 & $64.10(-1.7)$ & $62.61(0.39)$ \\
$\operatorname{Ti}(\mathrm{o})-\mathrm{Si}(\mathrm{t})$ & 4.59 & $64.49(-1.32)$ & $63.24(1.02)$ \\
$\operatorname{Ti}(\mathrm{o})-\mathrm{Ti}(\mathrm{o})$ anatase structure & 3.08 & $65.81(0.00)$ & \\
\hline \hline
\end{tabular}

ticularly when $\mathrm{M}^{4+}$ can be bonded through two oxygen [i.e., clusters $\operatorname{Ti}(\mathrm{t})-\mathrm{Si}(\mathrm{t})-2$ and $\mathrm{Zr}(\mathrm{t})-\mathrm{Si}(\mathrm{t})-2]$ present the maximum $\Delta R_{\text {ea }}$ values.

Data in Tables I and II also show that differences in $\Delta \varepsilon$ have an opposite sign when $\mathrm{Si}^{4+}$ and $\mathrm{Ti}^{4+} / \mathrm{Zr}^{4+}$ cations are diluted within a network of, respectively, $\mathrm{TiO}_{2} / \mathrm{ZrO}_{2}$ and $\mathrm{SiO}_{2}$. In previous works, we have studied the evolution of the electronic parameters of oxide cations when a subnanometric thin film of one oxide is deposited on the surface of another oxide. ${ }^{6,32}$ In general, the observed differences in $\Delta \varepsilon$ were attributed to variations of the Madelung potential at the cation sites due to the different ionic character of the $\mathrm{M}-\mathrm{O}-\mathrm{M}^{\prime}$ bonds. A similar interpretation can be accepted here. Thus, in samples where few percents of $\mathrm{Si}$ ions are distributed within a network of $\mathrm{TiO}_{2} / \mathrm{ZrO}_{2}$, silicon will always have titanium/zirconium atoms as second neighbors. In this structure, the linking oxide ions will be rather ionic and contribute through a change in the Madelung potential to decrease the initial state energy of silicon with respect to the value in $\mathrm{SiO}_{2}$. A reverse effect can be assumed for the titanium which, for the diluted conditions, will be surrounded by silicon as second neighbors. Here, a change from fourfold to sixfold coordination can be an additional reason for the observed effects. ${ }^{4,10}$ The existence of this kind of mixed structures where silicon and titanium/zirconium ions are linked by oxide ions with different electronic characteristics that in the bulk oxides has been previously evidenced by FTIR. ${ }^{4,19,33}$ Intermediate species can be tentatively attributed to oxygen ions bonded to silicon and titanium/zirconium (i.e., $\mathrm{Si}-\mathrm{O}-\mathrm{Ti}$ and $\mathrm{Si}-\mathrm{O}-\mathrm{Zr}$ bond structures). The existence of such bonding structures has been previously evidenced by FTIR for the $\mathrm{Si}-\mathrm{Ti}-\mathrm{O}$ thin films ${ }^{19,33}$ and $\mathrm{Si}-\mathrm{Zr}-\mathrm{O} .^{34}$

\section{B. Band gap and composition of the films}

Band gap energies of the different samples have been determined by both optical and REELS measurements. The distribution of electron density of the valence band of the different samples has been also reported in Figs. 1 and 2. The $E_{g}$ values obtained by optical and REELS analysis are equivalent and define a tendency characterized by a sharp decrease from the value of $\mathrm{SiO}_{2}$ to that of the sample with $2 \%$ Ti. Then, it follows a smooth linear decay up to reach the situation of $\mathrm{TiO}_{2}$. The appearance of band states induced by the presence of titanium ions in the system is responsible for this type of behavior. A narrowing of the electron density

TABLE IV. $E_{g}$ and $R_{\text {ea }}$ evaluated by QM cluster calculation (see Fig. 9). The energy of free $\mathrm{Zr}^{+4} \rightarrow \mathrm{Nb}^{+5}$ or free $\mathrm{Si}^{+4} \rightarrow \mathrm{P}^{+5}$ has been subtracted to all the $R_{\text {ea }}$ values given in the table. The corresponding $\Delta R_{\text {ea }}$ are indicated in parenthesis.

\begin{tabular}{cccc}
\hline \hline Model & $E_{g}(\mathrm{eV})$ & $\begin{array}{c}R_{\mathrm{ea}}\left(\Delta R_{\mathrm{ea}}\right)(\mathrm{eV}) \\
\mathrm{Zr}^{4+} \rightarrow \mathrm{Nb}^{5+}\end{array}$ & $\begin{array}{c}R_{\mathrm{ea}}\left(\Delta R_{\mathrm{ea}}\right)(\mathrm{eV}) \\
\mathrm{Si}^{4+} \rightarrow \mathrm{P}^{5+}\end{array}$ \\
\hline $\mathrm{Si}(\mathrm{t})-\mathrm{Si}(\mathrm{t})-1$ & 7.72 & & $62.22(0.00)$ \\
$\mathrm{Zr}(\mathrm{t})-\mathrm{Si}(\mathrm{t})-1$ & 6.49 & $48.33(-1.24)$ & $62.62(0.40)$ \\
$\mathrm{Zr}(\mathrm{t})-\mathrm{Si}(\mathrm{t})-2$ & 5.18 & $47.78(-1.79)$ & $62.86(0.64)$ \\
$\mathrm{Zr}(\mathrm{o})-\mathrm{Si}(\mathrm{t})-1$ & 5.99 & $48.35(-1.22)$ & $62.95(0.73)$ \\
$\mathrm{Zr}(\mathrm{o})-\mathrm{Zr}(\mathrm{o})$ monoclinic & 5.6 & $49.57(0.00)$ & \\
\hline \hline
\end{tabular}


distribution in the valence band can be also deduced from the $\mathrm{X}$-ray photoemission spectra reported in Figs. 1 and 2 .

The narrowing of the band gap as the concentration of $\mathrm{Zr} / \mathrm{Ti}$ in the films increases has been also reproduced by the QM calculations with cluster models (see Tables III and IV). In fact, the calculated $E_{g}$ data in Tables III and IV, although not always in a good quantitative agreement with the experimental band gaps, clearly evidence that the band gap energy of pure $\mathrm{SiO}_{2}$ drops drastically when $\mathrm{Si}-\mathrm{O}-\mathrm{M}$ (M: Ti, $\mathrm{Zr}$ ) bond structures are present in the system.

\section{Correlation between local electronic parameters and macroscopic optical properties}

The classical theory of dielectrics ${ }^{35,36}$ provides the way to correlate extensive and local dielectric properties of a given material. The microscopic electronic polarizability $\alpha_{e}$ correlates the local field at a given position and the dipole moment induced by this local field. It is a measurement of the ability of the electronic clouds around the ions to move as a response to the local electric fields to form permanent dipoles. The microscopic electronic polarizability $\alpha_{e}$ is related to the macroscopic refractive index $n$ by the general refractivity formula,

$$
\alpha_{e}=\frac{W}{\rho} f(n),
$$

where $W$ is the molecular weight in $\mathrm{g} / \mathrm{mol}, \rho$ is the density in $\mathrm{g} / \mathrm{cm}^{3}$, and $f(n)$ is a function of the refractive index that takes the general form

$$
f(n)=\frac{n^{2}-1}{4 \pi+b\left(n^{2}-1\right)},
$$

where $b$ is a dimensionless constant. In the case of point dipole ions and cubic symmetry without overlap of the electron distribution, $b=4 \pi / 3$ so $f(n)=\left(n^{2}-1\right) /\left(n^{2}+2\right)$, and Eq. (1) takes the well-known Lorentz-Lorenz form. ${ }^{37}$ Introducing covalency (i.e., overlapping between electron distributions) leads to lower values of $b$ as it is reported for silicates, for which $b=1.2-1.3 .^{36}$ In any case, the dependence of the electronic polarizability with the refractive index is a smooth increasing function of $n$.

In a previous publication on $\mathrm{Al}-\mathrm{Ti}-\mathrm{O}$ thin films, we correlated the Auger parameter of $\mathrm{Ti}$ with the optical properties of the films, evidenced by the values of $n$ as the Ti/Al ratio varied. ${ }^{8}$ Such a correlation between an extensive magnitude such as $n$ and a local prove (i.e., the Auger parameter) is possible through the Eqs. (1) and (2). In particular, it is found that, to a good approximation, $\alpha_{e}$ is proportional to $f(n)$ $=\left(n^{2}-1\right) /\left(n^{2}+2\right)^{8}$ (i.e., Lorentz-Lorenz approximation).

In our case, the changes in electronic parameters of $\mathrm{Ti} / \mathrm{Zr}$ and $\mathrm{Si}$ can be related to the optical properties of the thin films in the same manner. In particular, it has been shown that the refractive index $n$ of the $\mathrm{Si}-\mathrm{Ti}-\mathrm{O}$ and $\mathrm{Si}-$ $\mathrm{Zr}-\mathrm{O}$ mixed oxide films increase with the content of $\mathrm{Ti}$ and $\mathrm{Zr}$, respectively (see Fig. 4). This increase runs in parallel to the Auger parameter as the mixed oxide composition changes (cf. Figs. 7 and 8).

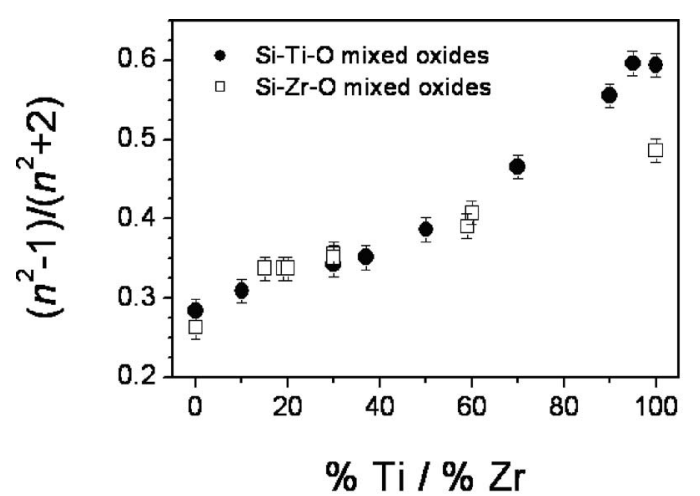

FIG. 10. $\left(n^{2}-1\right) /\left(n^{2}+2\right)$ as a function of the Ti (bold dots) or $\mathrm{Zr}$ (open squares) content in the mixed oxide thin films.

The main contribution to the electronic polarizability in mixed oxide systems comes from the oxygen ions. ${ }^{38}$ Changes in extra-atomic relaxation energies of a given cation in an oxide (note that oxygen atoms are always their nearest neighbors) show up as variations of the Auger parameter. This is the reason why the Auger parameter is so sensitive to the electronic polarizability of the system. The effect is as strong at the $\mathrm{Si}$ sites as at $\mathrm{Ti} / \mathrm{Zr}$ sites (similar $\Delta \alpha^{\prime}{ }_{\max }$ observed) for the two systems studied. Thus, variations in the Auger parameter of cations in mixed oxide system, disregarding the type of cation, correlate qualitatively with changes in the electronic polarizabilities of the oxygen anions in the corresponding compounds.

Figure 10 shows $\left(n^{2}-1\right) /\left(n^{2}+2\right)$ as a function of the $\mathrm{Ti} / \mathrm{Zr}$ content in the films ( $n$ taken at $550 \mathrm{~nm}$ ). It is apparent that in both cases this function varies in a similar way with the percentage of $\mathrm{Ti} / \mathrm{Zr}$, thus indicating that the two curves are generated by similar physical phenomena. It is only for $\mathrm{Ti} / \mathrm{Zr}$ content larger than $60 \%$ that they differ significantly from each other. As mentioned before, $\alpha_{e}$ [and hence $\left(n^{2}\right.$ $\left.-1) /\left(n^{2}+2\right)\right]$ is related with the ease by which the electron cloud around a given ion can be reorganized to create a local electronic dipole. Meanwhile, differences in Auger parameter with respect to a reference compound are a measure of the different relaxation energies of the photoholes once the photoemission event has taken place. ${ }^{6}$ In dielectric materials, the main mechanism for the screening of the photoholes is the formation of local dipoles in the surrounding medium. ${ }^{30}$ The ease with which these local dipoles are formed around the photoemitting atom depends on $\alpha_{e}$ and hence would be connected with the value of $\left(n^{2}-1\right) /\left(n^{2}+2\right)$.

An apparent misfit in the plots of Fig. 7 is the low value of $\alpha^{\prime}{ }_{\mathrm{Ti}}$ for the samples with the minimum content of Ti. This deviation from the linear relationship defined by the other samples can be related with the actual local structure around $\mathrm{Ti}$ in each case. It has been proven by $\mathrm{x}$-ray absorption spectroscopy that the Ti ions in the 2\%-10\% samples are fourfold coordinated $^{9}$ and that the coordination increases up to six with the percentage of this element. It has been previously reported $^{6,30}$ that the changes in the Auger parameter of oxides are the result of two contributions, a larger one due to the nearest coordination sphere and a second one due to the polarization of the rest of the matrix. We attribute the loss of linearity of the two samples with a small Ti content to this 


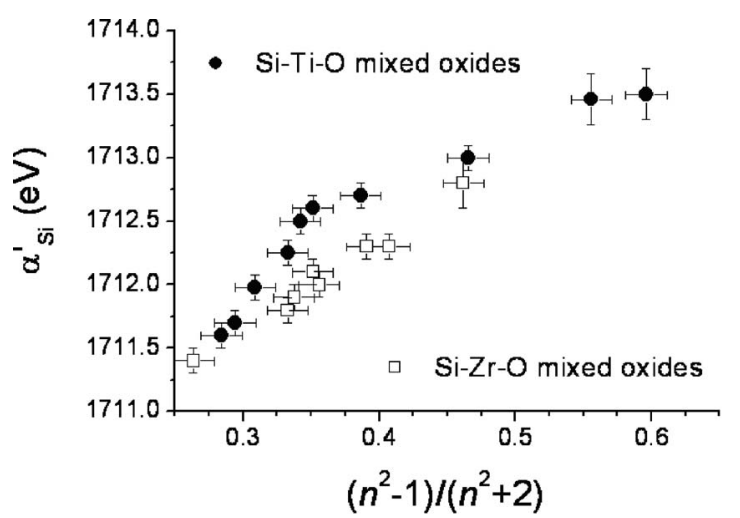

FIG. 11. Correlation between $\left(n^{2}-1\right) /\left(n^{2}+2\right)$ and the Auger parameter $\alpha^{\prime}{ }_{\mathrm{Si}}$ of $\mathrm{Si}-\mathrm{Ti}-\mathrm{O}$ (bold dots) and $\mathrm{Si}-\mathrm{Zr}-\mathrm{O}$ (open squares) mixed oxide thin films.

fourfold coordination. Recently, Moretti et al. ${ }^{39}$ have identified four coordinated titanium ions in titanosilicate compounds. The Auger parameter of these ions was much smaller than that of six-coordinated $\mathrm{Ti}^{4+}$, a similar tendency than that found in our thin films.

Figure 11 shows the correlation between the electronic polarizability, through the $\left(n^{2}-1\right) /\left(n^{2}+2\right)$ function, and the $\alpha^{\prime}{ }_{\mathrm{Si}}$ for $\mathrm{Si}-\mathrm{Ti}-\mathrm{O}$ and $\mathrm{Si}-\mathrm{Zr}-\mathrm{O}$ mixed oxides. We observe that there exists a quasilinear correlation between these two magnitudes, disregarding the type of mixed oxide considered. In fact, it is remarkable that larger range of variation in electronic polarizability is correlated to larger range of variation of the Auger parameter. Besides, the steeper initial variation of the $\mathrm{Si}-\mathrm{Ti}-\mathrm{O}$ system might be related to the larger difference for this system between extra-atomic relaxation energies observed in the QM calculation between $\operatorname{Si}(\mathrm{t})-\mathrm{M}(\mathrm{t})$ and $\mathrm{Si}(\mathrm{t})-\mathrm{M}(\mathrm{o})$ clusters.

\section{CONCLUSIONS}

Variation of local electronic parameters obtained by standard XPS analysis as the Auger parameter, extra-atomic relaxation energies, or binding energy of core levels in mixed oxide thin films can be easily correlated to extensive optical properties as the refractive index within the framework of the classical theory of dielectrics. It is shown that the Auger parameter in mixed oxides correlates linearly with the electronic polarizability obtained from the refractive index through the Lorentz-Lorenz relationship. In particular it is shown that the Auger parameter of $\mathrm{Si}$ in $\mathrm{Si}-\mathrm{Ti}-\mathrm{O}$ and $\mathrm{Si}-$ $\mathrm{Zr}-\mathrm{O}$ mixed oxide thin films can be used as a way to asses their refractive index. This method might be very useful to quantify optically ultrathin films $(<10 \mathrm{~nm})$ where optical methods are difficult to apply to determine $n$. QM cluster calculations support the experimental findings and the correlations established between the local electronic parameters and the extensive optical properties of the mixed oxide phases.

\section{ACKNOWLEDGMENTS}

We thank the Spanish Ministry of Science and Education for financial support (Grant Nos. MAT2004-01558 and CTQ2004-00582).

${ }^{1}$ M. Cevro, Thin Solid Films 258, 91 (1995).

${ }^{2}$ B. Gallas, A. Brunet-Bruneau, S. Fisson, G. Vuye, and J. Rivory, J. Appl. Phys. 92, 1922 (2002).

${ }^{3}$ M. Nogami, J. Non-Cryst. Solids 69, 415 (1985).

${ }^{4}$ F. Gracia, F. Yubero, J. P. Holgado, J. P. Espinós, A. R. González-Elipe, and T. Girardeau, Thin Solid Films 500, 19 (2006).

${ }^{5}$ C. D. Wagner, Faraday Discuss. Chem. Soc. 60, 291 (1975).

${ }^{6}$ A. R. González-Elipe and F. Yubero, in Spectroscopic Characterization of Oxide/Oxide Interfaces, Handbook of Surfaces and Interfaces of Materials Vol. 2, edited by H. S. Nalwa (Academic, San Diego, 2001), p. 147.

${ }^{7}$ A. von Richthofen, R. Cremer, R. Domnick, and D. Neuschütz, Thin Solid Films 315, 66 (1998).

${ }^{8}$ F. Yubero, A. Stabel, and A. R. González-Elipe, J. Vac. Sci. Technol. A 16, 3477 (1998).

${ }^{9}$ G. Moretti, J. Electron Spectrosc. Relat. Phenom. 95, 95 (1998).

${ }^{10}$ J. A. Mejías, V. M. Jiménez, G. Lassaletta, A. Fernández, J. P. Espinós, and A. R. González-Elipe, J. Phys. Chem. 100, 16225 (1996).

${ }^{11}$ A. Barranco, F. Yubero, J. A. Mejías, J. P. Espinós, and A. R. GonzálezElipe, Surf. Sci. 482-485, 680 (2001)

${ }^{12}$ S. M. Lee, J. H. Park, K. S. Hong, W. J. Cho, and D. L. Kim, J. Vac. Sci. Technol. A 18, 2384 (2000).

${ }^{13}$ H. Niederwald, Thin Solid Films 377-378, 21 (2000).

${ }^{14}$ G. M. Rignanese, F. Detraux, X. Gonze, and A. Pasquarello, Phys. Rev. B 64, 134301 (2001).

${ }^{15}$ J. Robertson, J. Vac. Sci. Technol. B 18, 1785 (2000).

${ }^{16}$ F. Gracia, F. Yubero, J. P. Espinós, J. P. Holgado, A. R. González-Elipe, and T. Girardeau, Surf. Interface Anal. 38, 752 (2006).

${ }^{17}$ A. R. González-Elipe, F. Yubero, and J. M. Sanz, Low Energy Ion Assisted Film Growth (Imperial College Press, London, 2003), p. 58.

${ }^{18}$ F. Gracia, J. P. Holgado, and A. R. González-Elipe, Langmuir 20, 1688 (2004).

${ }^{19}$ F. Gracia, Ph.D. thesis, University of Sevilla, Spain, 2005 Available on the web (http://sincaf-icmse.es/en/presentations).

${ }^{20}$ F. J. Ferrer, Ph.D. thesis, University of Sevilla, Spain, 2007. Available on the web (http://sincaf-icmse.es/en/presentations).

${ }^{21}$ R. G. Parr and W. Yang, Density-Functional Theory of Atoms and Molecules (Oxford University Press, Oxford, 1989).

${ }^{22}$ A. D. Becke, J. Chem. Phys. 98, 5648 (1993).

${ }^{23}$ G. A. Petersson and M. A. Al-Laham, J. Chem. Phys. 94, 6081 (1991).

${ }^{24}$ X. Y. Cao and M. Dolg, J. Chem. Phys. 115, 7348 (2001).

${ }^{25}$ M. E. Casida, C. Jamorski, K. C. Casida, and D. R. Salahub, J. Chem. Phys. 108, 4439 (1998).

${ }^{26}$ M. J. Frisch et al., Computer code GAUssian 03 Revision B04 (Gaussian, Pittsburgh, PA, 2003).

${ }^{27}$ L. A. J. Garvie, P. Rez, J. R. Alvarez, and P. R. Busek, Solid State Commun. 106, 303 (1998).

${ }^{28}$ F. Yubero, J. M. Sanz, J. F. Trigo, E. Elizalde, and S. Tougaard, Surf. Interface Anal. 22, 124 (1994)

${ }^{29}$ R. H. French, S. J. Glass, F. S. Ohuchi, Y. N. Xu, and W. Y. Ching, Phys. Rev. B 49, 5133 (1994),

${ }^{30}$ J. Morales, J. P. Espinós, A. Caballero, A. R. González-Elipe, and J. A. Mejías, J. Phys. Chem. 109, 7758 (2005).

${ }^{31}$ G. Lucovsky and G. B. Rayner, Jr., Appl. Phys. Lett. 77, 2912 (2000).

${ }^{32}$ F. Yubero, C. Mansilla, F. J. Ferrer, J. P. Holgado, and A. R. GonzálezElipe, J. Appl. Phys. 101, 124910 (2007).

${ }^{33}$ H. Larouche, J. E. Szymanowski, L. J. Klemberg-Sapieha, and J. Murtinu, J. Vac. Sci. Technol. A 22, 1200 (2004).

${ }^{34}$ G. Lucovsky, G. B. Rayner, D. Kang, C. L. Hinkle, and J. G. Hong, Appl. Surf. Sci. 234, 429 (2004).

${ }^{35}$ O. L. Anderson and E. Schreiber, J. Geophys. Res. 70, 1463 (1965).

${ }^{36}$ J. Arndt and W. Hummel, Phys. Chem. Miner. 15, 363 (1988).

${ }^{37} \mathrm{Ch}$. Kittel, Introduction to Solid State Physics (Wiley, New York, 2005).

${ }^{38}$ J. R. Tessman and A. H. Kahn, Phys. Rev. 92, 890 (1953).

${ }^{39}$ G. Moretti, A. M. Salvi, M. R. Guascito, and F. Langerame, Surf. Interface Anal. 36, 1402 (2004). 